\title{
Desempenho de forrageiras em sistemas alagados de tratamento de águas residuárias do processamento do café
}

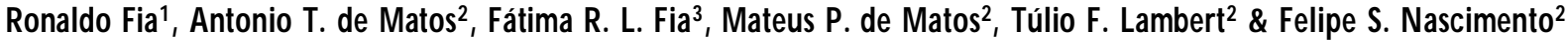

\section{RESU MO}

Duas gramíneas forrageiras de inverno, azevém (Lolium multiflorum) e aveia preta (Avena strigosa Schreb), foram cultivadas em sistemas alagados construídos (SACs) utilizados no tratamento das águas residuárias do processamento dos frutos do cafeeiro (ARC) com o objetivo de se avaliar seu desempenho agronômico. Essas forrageiras foram submetidas a diferentes cargas orgânicas (650 a $1.500 \mathrm{~kg} \mathrm{ha}^{-1} \mathrm{~d}^{-1}$ de D Q 0 ), proporcionadas pela aplicação dos efluentes de filtros anaeróbios, utilizados no tratamento da ARC. Como tratamento testemunha, as mesmas espécies vegetais foram cultivadas em solução de Hoagland. A matéria seca produzida pelas forrageiras ao longo dos 53 dias de monitoramento dos SACs variou de 7,4 a 14,0 e 0,5 a 2,7 tha-1 , e os rendimentos acumulados de proteína bruta variaram de 1.017 a 2.187 e 66,6 a $316,8 \mathrm{~kg} \mathrm{ha}^{-1}$ para 0 azevém e a aveia, respectivamente. $0 \mathrm{~s}$ resultados permitiram concluir que, dentre as forrageiras estudadas, o azevém se mostrou mais adequado para ser cultivado em SACs utilizados no pós-tratamento da ARC efluente de filtros anaeróbios, já que apresentou maior rendimento de matéria seca e proteína bruta e, portanto, melhor adaptação ao sistema.

Palavras-chave: Tratamento de efluentes, água residuária agroindustrial, café, Lolium multiflorum, Avena strigosa

\section{Performance of forage crops in wetlands used in the treatment of wastewater of coffee processing}

\begin{abstract}
Two winter grasses, ryegrass (Lolium multiflorum) and oats (Avena strigosa Schreb), were grown in constructed wetlands (SACs) used in the treatment of wastewater of coffee processing (ARC) with the aim to evaluate their agronomic performance. These forage crops were submitted to different organic loads (650 to $1500 \mathrm{~kg} \mathrm{ha}^{-1} \mathrm{~d}^{-1}$ of CO D), offered by the application of anaerobic effluent filters, used in the treatment of ARC. As a control treatment, the same plant species were grown in a Hoagland solution. The forage dry matter produced by over 53 days of monitoring SACs ranged from 7.4 to 14.0 and from 0.5 to $2.7 \mathrm{tha}^{-1}$, and the crude protein yield ranged from 1017 to 2187 and 66.6 to $316.8 \mathrm{~kg} \mathrm{ha}^{-1}$ for ryegrass and oats, respectively. The results show ed that, among the forages studied, the ryegrass was more suitable to be grown in SACs used in the post-treatment of ARC anaerobic effluent filters, presenting higher dry matter yield and crude protein, and therefore better adaptation to the system.
\end{abstract}

Key words: wastewater treatment, wastewater agro-industry, coffee, Lolium multiflorum, Avena strigosa

\footnotetext{
1 DEG/U FLA. CP 3037, Campus da UFLA, CEP 37200-000, Lavras, MG. Fone: (35) 3829-1481. E-mail: ronaldofia@deg.ufla.br

2 DEA/UFV. Av. PH Rolfs, s/n, Campus da UFV, CEP 36570-000, Viçosa, MG. Fone: (31) 3899-2729. E-mail: atmatos@ufv.br; mateus.matos@ufv.br; tulioflambert@hotmail.com; felipskt@yahoo.com.br

3 IFMG, Campus Bambuí. Fazenda Varginha, Rodovia Bambuí/M edeiros, km 05, CEP 38900-000, Bambuí, MG. Fone: (37) 3431-4900. E-mail: fatima.fia@ifmg.edu.br
} 


\section{INTRODUÇÃO}

O impacto ambiental proporcionado pelas águas residuárias da lavagem e descascamento/despolpa dos frutos do cafeeiro (ARC) é grande, não somente pela carga orgânica contaminante que alcança os corpos d'água mas, também, pelo volume de águas limpas utilizado no processamento do fruto e que é devolvido ao meio ambiente com baixa qualidade (Matos et al., 2005). Diversos métodos têm sido propostos para o tratamento de águas residuárias ricas em material orgânico; dentre os mais recentes estão os sistemas alagados construídos (SACs), também conhecidos como sistemas wetlands.

Os SACs são projetados de forma a possibilitarem o cultivo de espécies vegetais em substratos constituídos por areia, solo ou brita, onde ocorre a formação de biofilme que agrega populações variadas de micro-organismos que, por meio de processos biológicos, químicos e físicos, possibilitam o tratamento das águas residuárias (Matos \& Lo Mônaco, 2003). A vegetação implantada nesses leitos de cultivo atua como extratora de macro e micronutrientes necessários ao seu crescimento, além de poder transferir oxigênio para o substrato, permitindo a formação de sítios aeróbios em torno de rizomas e raízes. Essas plantas também favorecem o desenvolvimento dos filmes biologicamente ativos que propiciam a degradação dos compostos orgânicos, depurando o meio (Tanner, 2001).

Diversas espécies vegetais dos gêneros Typha, Phagmites e Scirpus, naturalmente adaptadas a ambientes alagados, têm sido implantadas nesses sistemas (Brasil et al., 2007). Outras espécies vegetais da família das gramíneas, como o capim tifton-85 (Cynodon sp.) e o capim elefante (Pennisetum purpureum), adaptadas às condições tropicais, também têm sido utilizadas com sucesso, em SACs, no tratamento de águas residuárias agroindustriais (Lin et al., 2007; Matos et al., 2008; 2009); no entanto, não se encontram, na literatura SACs, cultivados com a aveia nem com o azevém.

A aveia preta é uma gramínea utilizada como forrageira de inverno, para pastejo direto ou conservação na forma de feno ou silagem. A aveia tem sido destinada ao manejo e conservação do solo, como cobertura e como adubação verde ou, ainda, para a semeadura direta, por ser produtora de grande quantidade de massa, de decomposição mais lenta que as leguminosas empregadas como adubo verde. Esta gramínea cresce e se desenvolve rapidamente auxiliando no controle de erosão e das plantas daninhas (Rossetto \& Nakawaga, 2001). O azevém também é uma gramínea forrageira de fácil implantação e utilização. É uma espécie muito versátil, que pode ser utilizada em pastagem cultivada de inverno, como melhoradora de pastagens naturais ou como cobertura visando ao plantio direto na primavera (Flores et al., 2008), sendo considerada importante planta daninha em culturas de trigo, soja e em pomares de macieira e pereira na região Sul do Brasil (Ferreira et al., 2008).

Considerando o fraco desempenho da Typha sp e da Alternanthera philoxeroides, quando cultivadas em SACs utilizados no tratamento de grandes cargas orgânicas, comumente presentes na ARC (Fia et al., 2008), e a estacionalidade da colheita e do processamento dos frutos do cafeeiro, torna-se recomendável a seleção de espécies de inverno que possam ser aproveitadas na alimentação animal. Desta forma se buscou, neste trabalho, avaliar o desempenho agronômico e o rendimento de matéria seca e da proteína bruta das espécies forrageiras azevém (Lolium multiflorum) e aveia preta (Avena strigosa Schreb), quando cultivadas em SACs utilizados no pós-tratamento da ARC efluente de filtros anaeróbios.

\section{MATERIAL E MÉTODOS}

O experimento foi conduzido na Área de Pré-processamento e Armazenamento de Produtos Agrícolas, do Departamento de Engenharia Agrícola, na Universidade Federal de Viçosa, Viçosa, MG. Para condução do experimento, seis SACs de escoamento subsuperficial horizontal foram construídos em escala piloto, constituídos por caixas $(0,4 \times 0,5$ x 1,5 m) de madeira de Pínus, impermeabilizadas por geomembrana de polietileno de alta densidade (PEAD), posicionadas sobre o solo em declividade de $0,01 \mathrm{~m} \mathrm{~m}^{-1}$. Como

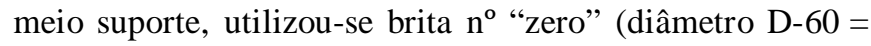
$7,0 \mathrm{~mm}$ e volume de vazios inicial de $0,491 \mathrm{~m}^{3} \mathrm{~m}^{-3}$ ). Os SACs foram preenchidos com a brita até a altura de $0,35 \mathrm{~m}$, deixando-se uma borda livre (não saturada) de $0,05 \mathrm{~m}$, já que o nível d'água foi mantido em $0,30 \mathrm{~m}$. Nos $\mathrm{SAC}_{1}, \mathrm{SAC}_{3} \mathrm{e}$ $\mathrm{SAC}_{5}$ se plantou a espécie azevém (Lolium multiflorum) e, nos $\mathrm{SAC}_{2}, \mathrm{SAC}_{4}$ e $\mathrm{SAC}_{6}$, a espécie aveia preta (Avena strigosa Schreb). O azevém foi plantado por meio de sementes $\left(30 \mathrm{~kg} \mathrm{ha}^{-1}\right)$ aplicadas a lanço sobre o leito de brita; a aveia também foi plantada a lanço $\left(80 \mathrm{~kg} \mathrm{ha}^{-1}\right)$; no entanto, devido à dificuldade na germinação, fez-se o transplantio aos 15 dias após a germinação (60 plantas $\mathrm{m}^{-2}$ ); decorridos 15 dias da implantação do sistema, foram aplicados, nos SACs, os efluentes de filtros anaeróbios, que foram alimentados com ARC diluída, com correção de pH até aproximadamente 7,0, com cal hidratada e com correção nutricional com uréia e superfosfato simples $(\mathrm{DBO} / \mathrm{N} / \mathrm{P}=100 / 5 / 1)$. As características da ARC diluída aplicada aos filtros e, posteriormente, aos SACs, estão apresentadas na Tabela 1 e as características operacionais dos seis SACs se acham na Tabela 2. O experimento foi monitorado durante 55 dias. Paralelamente aos SACs, cada espécie foi cultivada separadamente em três vasos preenchidos com brita zero e capacidade total de $8 \mathrm{~L}$, com a solução de Hoagland tradicional (Hoagland \& Arnon, 1950).

Tabela 1. Valores médios das principais características da água residuária do processamento dos frutos do cafeeiro (ARC) utilizada durante 0 monitoramento do sistema

\begin{tabular}{cr}
\hline Variáveis & \multicolumn{1}{c}{ ARC bruta } \\
pH & $3,44 \pm 0,16$ \\
DQO & $47.071 \pm 9,044$ \\
DBO & $13.471 \pm 3,999$ \\
FT & $127 \pm 19,00$ \\
N & $228 \pm 18,00$ \\
P & $30 \pm 17,00$ \\
K & $686 \pm 56,00$ \\
\hline
\end{tabular}

DQO, DBO, $\mathrm{N}$, P e K em mg L L-1; $\mathrm{F}_{\mathrm{T}}$ - concentração de fenóis totais, em $\mathrm{mg} \mathrm{L}^{-1}$ de ácido tânico 
Tabela 2. Características operacionais dos sistemas al agados construídos (SACS)

\begin{tabular}{|c|c|c|c|c|c|c|}
\hline \multirow{2}{*}{ Variáveis } & \multicolumn{3}{|c|}{ Azevém } & \multicolumn{3}{|c|}{ Aveia } \\
\hline & $\mathrm{SAC}_{1}$ & $\mathrm{SAC}_{3}$ & $\mathrm{SAC}_{5}$ & $\mathrm{SAC}_{2}$ & $\mathrm{SAC}_{4}$ & $\mathrm{SAC}_{6}$ \\
\hline Q & $0,068 \pm 0,008$ & $0,068 \pm 0,009$ & $0,066 \pm 0,008$ & $0,071 \pm 0,009$ & $0,072 \pm 0,009$ & $0,066 \pm 0,006$ \\
\hline TRH & $1,75 \pm 0,21$ & $1,75 \pm 0,22$ & $1,79 \pm 0,19$ & $1,68 \pm 0,22$ & $1,64 \pm 0,20$ & $1,78 \pm 0,15$ \\
\hline $\mathrm{TCO}_{\mathrm{A}-\mathrm{DBO}}$ & $464 \pm 126$ & $667 \pm 172$ & $750 \pm 164$ & $494 \pm 120$ & $660 \pm 163$ & $828 \pm 201$ \\
\hline $\mathrm{TCO}_{\mathrm{A}-\mathrm{D} 00}$ & $653 \pm 470$ & $1.297 \pm 305$ & $1.394 \pm 426$ & $686 \pm 447$ & $1.260 \pm 130$ & $1.531 \pm 444$ \\
\hline
\end{tabular}

Q - vazão $\left(\mathrm{m}^{3} \mathrm{~d}^{-1}\right) ; T R H$ - tempo de residência hidráulica (d); TCO $\mathrm{A}$ Taxa de carga orgânica tomada com base na área superficial $\left(\mathrm{kg} \mathrm{ha}^{-1} \mathrm{~d}^{-1}\right)$ e na DBO e DQO

Ao final do experimento realizou-se o corte dos vegetais, a fim de se avaliar a produtividade e os teores de nutrientes na parte aérea da vegetação. Nesta fase, as espécies cultivadas se encontravam no início da florescência. As amostras foram colocadas em sacos de papel e levadas à estufa, sob temperatura de $65^{\circ} \mathrm{C}$, com circulação de ar, até atingir massa constante (pressecagem). Em seguida, as amostras foram trituradas em moinho e armazenadas para posterior quantificação do conteúdo de matéria seca e realização da análise nutricional (N, P, K, Na, Ca e Mg), seguindo-se metodologia proposta pela EMBRAPA (1999). Obteve-se a conversão de $\mathrm{N}$ em proteína bruta multiplicando-se o valor deste por 6,25 (Silva, 1990).

A quantificação dos aportes de nutrientes (nitrogênio, fósforo e potássio) (Tabela 3) foi obtida por meio de valores de concentrações determinadas no afluente ao sistema, feitas em cinco amostragens e depois multiplicadas pelos volumes afluentes diários, que foram determinados por medições diretas.

A capacidade das plantas em extrair nutrientes foi obtida pelo produto da concentração do nutriente na planta e a produtividade da matéria seca (Eq. 1).

$$
\mathrm{CEN}=\mathrm{CN} \times \mathrm{MS} \times 10
$$

em que:

CEN - capacidade de extração de nutrientes, $\mathrm{kg} \mathrm{ha}^{-1}$

$\mathrm{CN}$ - concentração do nutriente na matéria seca da planta, dag $\mathrm{kg}^{-1}$

MS - conteúdo de matéria seca, dag $\mathrm{kg}^{-1}$

\section{RESULTADOS E DISCUSSÃO}

O plantio a lanço sobre o leito de brita não foi obstáculo para a germinação das sementes nem para o desenvolvimento do azevém; entretanto, a aveia apresentou germinação deficiente, tal como observado por Gomes Filho et al. (2001), necessitando de transplantio. Mesmo após o transplantio o desenvolvimento da aveia foi lento e as maiores plantas observadas no $\mathrm{SAC}_{2}$ não ultrapassaram $0,25 \mathrm{~m}$ de altura, após 50 dias da germinação.
Na Figura 1 se apresentam os valores médios da produtividade de matéria seca do azevém e da aveia, em $\mathrm{t}$ ha-1, cultivados nos SACs e nos vasos que serviram de testemunha, durante o período experimental.

Apesar de alguns autores (Kichel \& Miranda, 2000; Souza

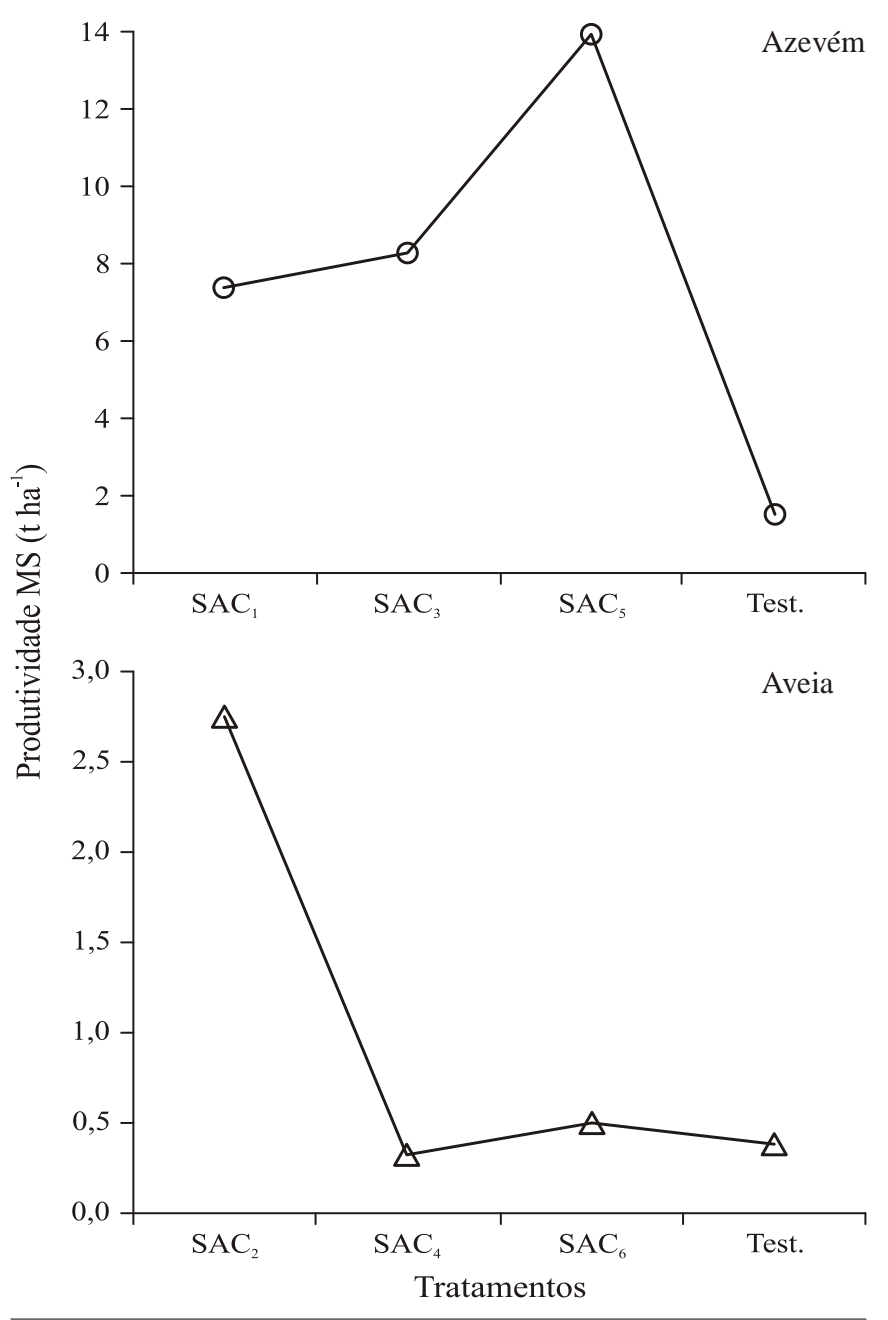

Figura 1. Valores médios da produtividade de matéria seca do azevém e da aveia cultivados nos SACs $\left(\mathrm{SAC}_{1}=653 \pm 470 ; \mathrm{SAC}_{2}=686 \pm 447\right.$; $\mathrm{SAC}_{3}=1.297 \pm 305 ; \mathrm{SAC}_{4}=1.260 \pm 130 ; \mathrm{SAC}_{5}=1.394 \pm 426 \mathrm{e}$ $\mathrm{SAC}_{6}=1.531 \pm 444 \mathrm{~kg} \mathrm{ha}^{-1} \mathrm{~d}^{-1}$ de DQO) e nos vasos testemunha

Tabela 3. Q uantidade média de nutrientes aplicada nos SACs (kg ha-1 $\left.\mathrm{d}^{-1}\right)$

\begin{tabular}{|c|c|c|c|c|c|c|}
\hline \multirow{2}{*}{ Variáveis } & \multicolumn{3}{|c|}{ Azevém } & \multicolumn{3}{|c|}{ Aveia } \\
\hline & $\mathrm{SAC}_{1}$ & $\mathrm{SAC}_{3}$ & $\mathrm{SAC}_{5}$ & $\mathrm{SAC}_{2}$ & $\mathrm{SAC}_{4}$ & $\mathrm{SAC}_{6}$ \\
\hline $\mathrm{N}$ & $19,7 \pm 8,6$ & $25,2 \pm 7,8$ & $28,7 \pm 7,6$ & $20,9 \pm 8,5$ & $24,1 \pm 5,1$ & $31,7 \pm 9,0$ \\
\hline$P$ & $2,5 \pm 1,6$ & $2,8 \pm 1,7$ & $3,2 \pm 1,6$ & $2,8 \pm 2,8$ & $2,9 \pm 1,9$ & $3,5 \pm 1,7$ \\
\hline $\mathrm{K}$ & $39,0 \pm 6,7$ & $60,1 \pm 9,9$ & $63,3 \pm 7,8$ & $41,7 \pm 6,7$ & $60,6 \pm 15,5$ & $69,4 \pm 6,5$ \\
\hline
\end{tabular}


et al., 2005) citarem a intolerância da aveia às condições de alagamento, Gomes Filho et al. (2001) obtiveram valores de produtividade de matéria verde de 0,3 a $8,6 \mathrm{t} \mathrm{ha}^{-1}$, após 42 dias de cultivo da aveia, em condições hidropônicas com águas residuárias da suinocultura com diferentes diluições. A maior produtividade de massa verde de aveia foi obtida neste experimento, no $\mathrm{SAC}_{2}$ (receptor da menor carga orgânica $-\mathrm{TCO}_{\mathrm{A}}=686 \pm 447 \mathrm{~kg} \mathrm{ha}^{-1} \mathrm{~d}^{-1}$ de DQO), no qual se obtiveram 5,84 tha-1 (2,75 $\mathrm{t} \mathrm{ha}^{-1}$ de matéria seca), valor que não foi repetido no $\mathrm{SAC}_{4}$ nem no $\mathrm{SAC}_{6}$. Acredita-se que o desenvolvimento deficiente das plantas de aveia seja devido às elevadas cargas orgânicas aplicadas aos sistemas e às características da $\mathrm{ARC}$, diferentes daquelas apresentadas pela água residuária da suinocultura utilizada por Gomes Filho et al. (2001). Segundo Souza et al. (2005), dos numerosos compostos formados pelo metabolismo anaeróbico em ambientes alagados se destacam os ácidos orgânicos, especialmente os ácidos alifáticos de cadeia curta, como o acético, o propiônico e o butírico. Os efeitos tóxicos desses ácidos dependem do tipo e da concentração presente no meio; entretanto, o acúmulo desses compostos pode afetar, de forma irreversível, a produtividade final das culturas estabelecidas nesse sistema (Camargo et. al., 2001).

Em relação ao azevém, nota-se aumento na produtividade com o aumento da carga aplicada $\left(\mathrm{SAC}_{5}\right)$, o que não foi observado para a aveia, visto que houve queda acentuada de produtividade do $\mathrm{SAC}_{2}$ para os $\mathrm{SAC}_{4}$ e $\mathrm{SAC}_{6}$, diferente do que foi observado por Gomes Filho et al. (2001).

Em relação à produção de matéria seca produzida pelo azevém, nota-se grande diferença entre o que foi produzido pelas plantas testemunha e aquelas cultivadas nos SACs. A mesma afirmação não pode ser feita em relação à produtividade de matéria seca pelas plantas de aveia, já que foi pequena a diferença entre o que se obteve nas plantas testemunhas e aquelas cultivadas nos $\mathrm{SAC}_{4}$ e $\mathrm{SAC}_{6}$, os quais foram submetidos, respectivamente, às $\mathrm{TCO}_{\mathrm{A}}$ de $1.297 \pm 305$ e $1.394 \pm 426 \mathrm{~kg} \mathrm{ha}^{-1} \mathrm{~d}^{-1}$ de DQO.

Matos et al. (2003) obtiveram produtividade de 11,07 $\mathrm{t} \mathrm{ha}^{-1}$ de matéria seca de azevém quando cultivado em rampas de tratamento da ARC, em três cortes, totalizando um período de cultivo de 150 dias. No caso da aveia, a produtividade de matéria seca foi de 4,41 t ha-1 em um corte único, efetuado aos 68 dias após o plantio, mas a carga orgânica aplicada foi de $250 \mathrm{~kg} \mathrm{ha}^{-1} \mathrm{~d}^{-1}$, bem inferior às cargas aplicadas neste trabalho (Tabela 2). Destaca-se a produtividade do azevém obtida no $\mathrm{SAC}_{5}$, que foi o que recebeu a maior carga orgânica $\left(\mathrm{TCO}_{\mathrm{A}}\right.$ de $1.394 \pm 426 \mathrm{~kg} \mathrm{ha}^{-1} \mathrm{~d}^{-1}$ de DQO). Neste sistema a produtividade foi superior à obtida por Matos et al. (2003) e em aproximadamente um terço do tempo de cultivo.

Pauletti et al. (2008) colheram 2,6 t ha-1 de matéria seca de aveia, quando submetida à adubação química convencional, enquanto Kichel \& Miranda (2000) citam que a produtividade de matéria seca da aveia pode variar entre 2 e $6 \mathrm{t} \mathrm{ha}^{-1}$. Corrêa et al. (2007) avaliando 37 variedades de azevém obtiveram produção máxima de matéria seca no terceiro corte do azevém comum de 1,0 $\mathrm{t} \mathrm{ha}^{-1}$; esta produtividade foi obtida no intervalo de 30 dias entre os cortes.

$\mathrm{Na}$ Tabela 4 se apresentam os valores médios da concentração de nutrientes no tecido vegetal e as porcentagens médias de extração de nitrogênio, fósforo e potássio, pelo azevém e pela aveia, calculadas com base na produtividade e na concentração desses nutrientes na matéria seca.

Observa-se, na Tabela 4, que as concentrações de nutrientes no tecido foliar do azevém e da aveia ficaram muito próximas e, na maioria dos SACs, a aveia mostrou maior concentração de nutrientes em função, provavelmente, do menor efeito diluição ocasionado pela menor produção de biomassa. Da fração de nutrientes removida do sistema, o azevém foi mais eficiente que a aveia, fato justificado pela maior produção de biomassa do azevém e não, propriamente, pela capacidade de absorção das espécies avaliadas.

Brasil et al. (2007) e Matos et al. (2009) verificaram que a taboa (Typha sp.) foi responsável pela retirada de apenas 1,69 e 4,50; 1,64 e 2,3 e 4,90 e 12,7\% do N, P e K aportado ao sistema. Matos et al. (2009) também notaram, com o cultivo do capim tifton-85 (Cynodon dactylon Pers.) que em SACs utilizados no tratamento de águas da suinocultura, foram obtidos valores de 5,3; 3,3 e 11,7\% na remoção de $\mathrm{N}, \mathrm{P}$ e K, respectivamente. As eficiências obtidas com o cultivo do azevém nos SACs, neste experimento, foram superiores às indicadas pelos referidos autores, quando do cultivo da taboa e do capim tifton-85 em SACs, no tratamento de esgoto doméstico e água residuária da suinocultura, respectivamente porém neste trabalho as cargas de nutrientes aplicadas aos SACs (Tabela 3) foram inferiores àquelas aplicadas por Brasil et al. (2007) e Matos et al. (2009). Matos et al. (2008) ao avaliarem o capim tifton85 , verificaram que este, além de se adaptar bem aos SACs utilizados no tratamento de águas residuárias de laticínios, foi capaz de remover grandes quantidades de nutrientes que variaram de 216 a 544, 24 a 61 e 115 a $204 \mathrm{~kg} \mathrm{ha}^{-1}$, respectivamente para $\mathrm{N}, \mathrm{P}$ e $\mathrm{K}$.

Tabela 4. Valores médios da concentração de nutrientes no tecido vegetal e percentuais médios de remoção de N, P e K pelo azevém e pela aveia, quando cultivadas em SACs submetidos a diferentes cargas orgânicas provenientes da ARC efluente de filtros anaeróbios, e plantas testemunha

\begin{tabular}{|c|c|c|c|c|c|c|c|c|}
\hline \multirow{2}{*}{ Parâmetros } & \multicolumn{4}{|c|}{ Azevém } & \multicolumn{4}{|c|}{ Aveia } \\
\hline & $\mathrm{SAC}_{1}$ & $\mathrm{SAC}_{3}$ & $\mathrm{SAC}_{5}$ & Test. & $\mathrm{SAC}_{2}$ & $\mathrm{SAC}_{4}$ & $\mathrm{SAC}_{6}$ & Test. \\
\hline $\mathrm{N}\left(\right.$ dag $\left.\mathrm{kg}^{-1}\right)$ & 2,20 & 2,13 & 2,42 & 1,30 & 1,85 & 3,35 & 2,76 & 1,68 \\
\hline Remoção de N (\%) & 15,6 & 13,2 & 22,3 & - & 4,6 & 0,8 & 0,8 & - \\
\hline$P\left(\right.$ dag $\left.\mathrm{kg}^{-1}\right)$ & 0,16 & 0,16 & 0,18 & 0,13 & 0,24 & 0,22 & 0,19 & 0,14 \\
\hline Remoção de P (\%) & 9,0 & 8,8 & 15,0 & - & 4,5 & 0,5 & 0,5 & - \\
\hline $\mathrm{K}\left(\right.$ dag $\left.\mathrm{kg}^{-1}\right)$ & 2,0 & 3,0 & 3,4 & 2,8 & 2,5 & 2,1 & 2,1 & 0,70 \\
\hline Remoção de K (\%) & 7,2 & 7,8 & 14,2 & - & 3,1 & 0,2 & 0,3 & - \\
\hline
\end{tabular}

$\mathrm{SAC}_{1}=653 \pm 470 ; \mathrm{SAC}_{2}=686 \pm 447 ; \mathrm{SAC}_{3}=1.297 \pm 305 ; \mathrm{SAC}_{4}=1.260 \pm 130 ; \mathrm{SAC}_{5}=1.394 \pm 426$ e $\mathrm{SAC}_{6}=1.531 \pm 444 \mathrm{~kg} \mathrm{ha}^{-1} \mathrm{~d}^{-1}$ de $\mathrm{DQO}$ 
Os teores de nutrientes encontrados na matéria seca do azevém foram superiores aos encontrados por Soumaré et al. (2003), exceto para o $\mathrm{N}$ e K nas plantas testemunha e para o P, em todas as plantas avaliadas. Esses autores obtiveram $1,35,0,23$ e 2,02 dag $\mathrm{kg}^{-1}$, para $\mathrm{N}, \mathrm{P}$ e K para o azevém cultivado com diferentes adubações químicas. As menores concentrações de P na matéria seca do azevém, quando comparadas com as apresentadas na literatura (Soumaré et al., 2003), podem ser atribuídas à menor disponibilidade deste nutriente em função do tratamento da ARC com cal, formando compostos de baixa solubilidade, como o fosfato de cálcio. Os valores de $\mathrm{N}$ e K encontrados na matéria seca da aveia cultivada nos SACs deste experimento, foram superiores aos valores encontrados por Santi et al. (2003), que obtiveram concentrações de $\mathrm{N}$ e K de 1,50 e 1,89 dag $\mathrm{kg}^{-1}$, enquanto as concentrações de $\mathrm{P}$ foram semelhantes ( $\mathrm{P}$ igual a $0,20 \mathrm{dag} \mathrm{kg}^{-1}$ ) porém foram inferiores aos valores obtidos por Nakagawa \& Rosolem (2005) para N e P, quando avaliaram diferentes doses de adubação fosfatada e potássica e obtiveram concentrações na matéria seca da aveia de 4,10, 0,52 e

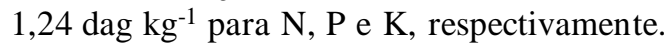

A aveia pode alcançar até 26 dag $\mathrm{kg}^{-1}$ de proteína bruta (Kichel \& Miranda, 2000), enquanto o azevém pode atingir 24 dag kg${ }^{-1}$ (Stivari \& Ribeiro Júnior, 2008). Os valores encontrados neste trabalho (Tabela 5) são inferiores aos valores máximos possíveis de serem obtidos porém estão próximos aos valores encontrados na literatura. Hellbrugge et al. (2008) obtiveram 13 dag kg-1 de proteína bruta em pastagens de azevém, no início do crescimento e $8 \mathrm{dag}^{-1} \mathrm{~g}^{-1}$ na fase final de crescimento. Moreira et al. (2007), ao avaliarem a proteína bruta em plantas de aveia cultivadas em sistema de plantio direto obtiveram, em média, 16,9 dag $\mathrm{kg}^{-1}$. Del Duca et al. (1999) obtiveram valores próximos a 16 dag $\mathrm{kg}^{-1}$. Barro et al. (2006) encontraram, para a aveia e o azevém, conteúdos de proteína bruta, respectivamente iguais a 11,5 e 14,5 dag $\mathrm{kg}^{-1}$, quando cultivados em local não sombreado.

Observando-se os dados apresentados na Tabela 5, temse que o azevém apresentou rendimentos acumulados de proteína bruta de 3 ( $\mathrm{SAC}_{1} / \mathrm{SAC}_{2}$ e testemunhas) a 25 vezes $\left(\mathrm{SAC}_{5} / \mathrm{SAC}_{6}\right)$ superiores aos apresentados pela aveia. $\mathrm{O}$ valor médio obtido de rendimento acumulado de proteína bruta pelo azevém no $\mathrm{SAC}_{5}$ foi superior aos $1.752,3 \mathrm{~kg} \mathrm{ha}^{-1}$ obtidos por Matos et al. (2003), ao cultivarem azevém em rampas de tratamento de ARC e aos 705,2 $\mathrm{kg} \mathrm{ha}^{-1} \mathrm{ano}^{-1}$ obtidos por Gomes \& Reis (1999), ao cultivarem azevém em condições de pastejo. No entanto, para a aveia os valores obtidos neste trabalho foram bem inferiores aos $640,8 \mathrm{~kg} \mathrm{ha}^{-1}$ obtidos por Matos et al. (2003) no cultivo da aveia, em condições semelhantes às do azevém, e aos $843,39 \mathrm{~kg} \mathrm{ha}^{-1} \mathrm{ano}^{-1}$ obtidos por Gomes \& Reis (1999).

De forma geral, o desempenho do azevém foi superior ao da aveia avaliada neste trabalho e da taboa e alternantera, quando cultivadas em SACs no tratamento da ARC, submetidas a cargas orgânicas semelhantes (Fia et al., 2008).

Torna-se importante ressaltar que as espécies vegetais cultivadas em SACs para o tratamento de águas residuárias devem ser eficientes na remoção de nutrientes do sistema, sobretudo de nitrogênio e fósforo, importantes fontes de poluição das águas; assim, pode-se considerar que o azevém é uma espécie apta a ser cultivada em SACs, principalmente em relação ao tratamento da ARC, produzida entre maio a agosto, período de temperaturas amenas, em que espécies tropicais apresentam dificuldades de desenvolvimento.

\section{CONCLUSÕES}

O azevém apresentou melhor comportamento agronômico (maior produtividade de matéria seca e proteína bruta) durante o período experimental, maior possibilidade de cortes e boa cobertura da superfície dos sistemas alagados construídos, sendo mais adequado para ser cultivado em sistemas utilizados no tratamento das águas residuárias do processamento dos frutos do cafeeiro, quando comparado à aveia.

\section{AGRADECIMENTOS}

Os autores agradecem à FAPEMIG (Bolsa de Pós-Doutorado) e ao $\mathrm{CNPq}$, pelo apoio financeiro concedido.

\section{LITERATURA CITADA}

Barro, R. S.; Saibro, J. C.; Silva, J. L. S.; Varella, A.; Pimenta, C. M.; Brambilla, D. M. Valor nutritivo de gramíneas anuais de inverno sob duas densidades de Pinus elliotii e sol pleno no RS. In: Reunião do Grupo Técnico em Forrageiras do Cone Sul, 21, Grupo Campos, Pelotas, 2006, Anais... Pelotas: GTFCS, 2006. CD-Rom.

Brasil, M. S.; Matos, A. T.; Soares, A. A. Plantio e desempenho fenológico da taboa (Typha sp.) utilizada no tratamento de esgoto doméstico em sistema alagado construído. Engenharia Sanitária e Ambiental, v.12, n.3, p.266-272, 2007.

Camargo, F. A.; Zonta, E.; Santos, G. A.; Rossielo, R. O. P. Aspectos fisiológicos e caracterização de toxidez a ácidos orgânicos voláteis em plantas. Ciência Rural, v.31, n.3, p.523-529, 2001.

Tabela 5. Proteína bruta (PB) e rendimento de proteína bruta (RPB) obtidos para as forrageiras quando aplicadas aos sistemas alagados construídos (SACS), durante o cultivo, diferentes cargas orgânicas provenientes da água residuária de processamento dos frutos do cafeeiro (ARC) e pelas testemunhas

\begin{tabular}{|c|c|c|c|c|c|c|c|c|}
\hline \multirow{2}{*}{ Parâmetros } & \multicolumn{4}{|c|}{ Azevém } & \multicolumn{4}{|c|}{ Aveia } \\
\hline & SAC1 & SAC3 & SAC5 & Test. & SAC2 & SAC4 & SAC6 & Test \\
\hline PB (dag kg ${ }^{-1}$ ) & 13,7 & 13,3 & 15,1 & 8,1 & 11,5 & 20,9 & 17,2 & 10,5 \\
\hline RPB $\left(\mathrm{kg} \mathrm{ha}^{-1}\right)$ & $1.017,2$ & $1.100,9$ & $2.107,5$ & 125,4 & 316,8 & 66,6 & 85,5 & 40,7 \\
\hline
\end{tabular}

$\mathrm{SAC}_{1}=653 ; \mathrm{SAC}_{2}=686 ; \mathrm{SAC}_{3}=1.297 ; \mathrm{SAC}_{4}=1.260 ; \mathrm{SAC}_{5}=1.394{\text { e } S A C_{6}}=1.531 \mathrm{~kg} \mathrm{ha}^{-1} \mathrm{~d}^{-1} \mathrm{de} \mathrm{DQO}$ 
Corrêa, B. O.; Mittelmann, A.; Stumpf, M. T.; Peres, M. M.; Duarte, P. R. Caracteres agronômicos em populações locais de azevém no sul do Brasil. Magistra, v.19, n.4, p.274-282, 2007.

Del Duca, L. J. A.; Guarienti, E. M.; Fontaneli, R. S.; Zanotto, D. L. Influência de cortes simulando pastejo na composição química de grãos de cereais de inverno. Pesquisa Agropecuária Brasileira, v.34, n.9, p.1607-1614, 1999.

EMBRAPA - Empresa Brasileira de Pesquisa Agropecuária. Manual de análises químicas de solos, plantas e fertilizantes. Brasília: EMBRAPA, 1999. 370p.

Ferreira, E. A.; Concenço, G.; Silva, A. A.; Reis, M. R.; Vargas, L.; Viana, R. G.; Guimarães, A. A.; Galon, L. Potencial competitivo de biótipos de azevém (Lolium multiflorum). Planta Daninha, v.26, n.2, p.261-269, 2008.

Fia, R. Matos, A. T.; Ferreira, P. A.; Teodoro, P. E. P.; Schuery, F. C.; Luiz, F. A. R. Desempenho agronômico da Thypha sp. e Alternanthera philoxeroides Mart. utilizadas no tratamento de águas residuárias da lavagem e descascamento/despolpa dos frutos do cafeeiro em sistema alagado construído. Engenharia na Agricultura, v.16, n.4, 436-448, 2008.

Flores, R. A.; Dall'Agnol, M.; Nabinger, C.; Montardo, D. P. Produção de forragem de populações de azevém anual no estado do Rio Grande do Sul. Revista Brasileira de Zootecnia, v.37, n.7, p.1168-1175, 2008.

Gomes Filho, R. R.; Matos, A. T.; Silva, D. D.; Martinez, H. E. P. Remoção de carga orgânica e produtividade da aveia forrageira em cultivo hidropônico com águas residuárias da suinocultura. Revista Brasileira de Engenharia Agrícola e Ambiental, v.5, n.1, p.131-134, 2001.

Gomes, J. F.; Reis, J. C. L. Produção de forrageiras anuais de estação fria no litoral sul do Rio Grande do Sul. Revista Brasileira de Zootecnia, v.28, n.4, p.668-674, 1999.

Hellbrugge, C.; Moreira, F. B.; Mizubuti, I. Y.; Prado, I. N.; Santos, B. P.; Pimenta, E. P. Desempenho de bovinos de corte em pastagem de azevém (Lolium multiflorum) com ou sem suplementação energética. Seminário: Ciências Agrárias, v.29, n.3, p.723-730, 2008.

Hoagland, D. R.; Arnon, D. I. The water-culture method for growing plants without soil. Berkeley: Califórnia Agricultural Experiment Station, 1950. 32p. Circular n.347.

Kichel, A. N.; Miranda, C. H. B. Uso da aveia como planta forrageira. Campo Grande: Embrapa Pecuária de Corte, 2000. Divulga n.45.

Lin, Y. F.; Jing, S. R., Lee, D. Y.; Chang, Y. F.; Shih, K. C. Nitrate removal and denitrification affected by soil characteristics in nitrate treatment wetlands. Journal of Environmental Science and Health, Part A, v.42, n.4, p.471-479, 2007.

Matos, A. T.; Abrahão, S. S.; Pereira, O. G. Desempenho agronômico de capim tifton 85 (Cynodon spp.) cultivado em sistemas alagados construídos utilizados no tratamento de água residuária de laticínios. Revista Ambiente e Água, v.3, n.1, p.43-53, 2008.
Matos, A. T.; Freitas, W. S.; Lo Mônaco, P. A. V. Capacidade extratora de diferentes espécies vegetais cultivadas em sistemas alagados utilizados no tratamento de águas residuárias da suinocultura. Revista Ambiente e Água, v.4, n.2, p.31-45, 2009.

Matos, A. T.; Lo Mônaco, P. A. Tratamento e aproveitamento agrícola de resíduos sólidos e líquidos da lavagem e despolpa dos frutos do cafeeiro. Viçosa: DEA/UFV, 2003. Boletim Técnico n.7.

Matos, A. T.; Pinto, A. B.; Pereira, O. G.; Barros, F. M. Alteração de atributos químicos no solo de rampas utilizadas no tratamento de águas residuárias. Revista Brasileira de Engenharia Agrícola e Ambiental, v.9, n.3, p.406-412, 2005.

Matos, A. T.; Pinto, A. B.; Pereira, O. G.; Soares, A. A.; Lo Mônaco, P. A. Produtividade de forrageiras utilizadas em rampas de tratamento de águas residuárias da lavagem e despolpa dos frutos do cafeeiro. Revista Brasileira de Engenharia Agrícola e Ambiental, v.7, n.1, p.154-158, 2003.

Moreira, A. L.; Reis, R. A.; Ruggieri, A. C.; Saran Júnior, A. J. Avaliação de forrageiras de inverno irrigadas sob pastejo. Ciência e Agrotecnologia, v.31, n.6, p.1838-1844, 2007.

Nakagawa, J.; Rosolem, C. A. Teores de nutrientes na folha e nos grãos de aveia-preta em função da adubação com fósforo e potássio. Bragantia, v.64, n.3, p.441-445, 2005.

Pauletti, V.; Barcellos, M.; Motta, A. C. V.; Monte Serrat, B.; Santos, I. R. Produtividade de culturas sob diferentes doses de esterco líquido de gado de leite e de adubo mineral. Scientia Agraria, v.9, n.2, p.199-205, 2008.

Rossetto, C. A. V.; Nakagawa, J. Época de colheita e desenvolvimento vegetativo de aveia preta. Scientia Agricola, v.58, n.4, p.731-736, 2001.

Santi, A.; Amado, T. J. C. Acosta, J. A. A. Adubação nitrogenada na aveia preta. I - Influência na produção de matéria seca e ciclagem de nutrientes sob sistema plantio direto. Revista Brasileira de Ciência do Solo, v.27, p.1075-1083, 2003.

Silva, D. J. Análises de alimentos (métodos químicos e biológicos). 2.ed. Viçosa: UFV, 1990. 165p.

Soumaré, M.; Tack, F. M. G.; Verloo, M. G. Effects of a municipal solid waste compost and mineral fertilization on plant growth in two tropical agricultural soils of Mali. Bioresource Technology, v.86, p.15-20, 2003.

Souza, V. Q.; Pereira, A. S.; Kopp, M. M.; Coimbra, J. L. M.; Carvalho, F. I. F.; Luz, V. K.; Oliveira, A. C. Dissimilaridade genética em mutantes de aveia tolerantes e sensíveis a ácidos orgânicos. Bragantia, v.64, n.4, p.569-575, 2005.

Stivari, A.; Ribeiro Júnior, J. R. Pastagem de inverno. São Paulo: SENAR, 2008. 15p. (Programa pecuária leiteira "ProLeite").

Tanner, C. C. Plants as ecosystem engineers in subsurface-flow treatment wetlands. Water Science Technology, v.44, n.11-12, p.9-17, 2001. 